\title{
FATOR DE RESPOSTA (Ky) DO FEIJOEIRO AO ESTRESSE HÍDRICO
}

\author{
João Alberto Fischer Filho ${ }^{1}$, João Luís Zocoler ${ }^{2}$, Nadia Maria Poloni ${ }^{3}$ \\ ${ }^{1}$ Doutorando em Agronomia / Ciência do Solo, Faculdade de Ciências Agrárias e Veterinárias, UNESP \\ Campus de Jaboticabal (SP). \\ ${ }^{2}$ Professor Adjunto - Departamento de Fitossanidade, Engenharia Rural e Solos da Faculdade de Engenharia / \\ UNESP Campus de Ilha Solteira (SP). \\ ${ }^{3}$ Mestranda em Agronomia / Sistemas de Produção, Faculdade de Engenharia / UNESP Campus de Ilha \\ Solteira (SP).
}

RESUMO: O feijoeiro é cultivado em praticamente todo Brasil, ficando exposto às diversas condições climáticas, cuja deficiência hídrica se torna um importante fator limitante à produção. O experimento foi conduzido em vasos em casa de vegetação, o delineamento experimental foi inteiramente casualizado, com seis tratamentos (níveis de estresse hídrico) e quatro repetições, sendo um tratamento diferenciado pela vedação da superfície do solo. A evapotranspiração medida no ciclo da cultura variou de 400 a $198 \mathrm{~mm}$, aumentando com o acréscimo de níveis de água disponível (AD) dos tratamentos. A produtividade de grãos e de matéria seca da parte área decresceu com a redução da $\mathrm{AD}$ e o tratamento onde ocorreu apenas transpiração apresentou melhor desempenho, e o fator de resposta da cultura foi 0,76 , caracterizando o feijoeiro como tolerante a deficiência hídrica.

Palavras-chave: Produtividade e matéria seca. Água disponível no solo. Evapotranspiração.

\section{BEAN YIELD RESPONSE FACTOR (Ky) UNDER WATER STRESS}

\begin{abstract}
Beans are grown in almost all agricultural areas in Brazil, being exposed to various weather conditions. Water stress becomes a major limiting factor to production. The experiment was conducted under greenhouse conditions, the experimental design was completely randomized, with six treatments (water stress levels) and four replications, being one treated differently by sealing the soil surface. The evaporation in the culture cycle ranged from 400 to $198 \mathrm{~mm}$, with higher values in those treatments with bigger levels of available water $(\mathrm{AD})$. Grain yield and dry matter decreased with the reduction of $\mathrm{AD}$. The treatment that occurred just evaporation showed the best level of performance, and the crop response factor was 0.76 . All together, these results characterize as a crop tolerant to water stress.
\end{abstract}

Key words: Grain yield and dry matter. Soil available water. Evapotranspiration.

\section{INTRODUÇÃO}

O feijoeiro comum (Phaseolus vulgaris, L.) é a leguminosa mais consumida no Brasil, sendo estimado em $16 \mathrm{~kg}$ o consumo anual per capita. O Brasil foi o terceiro maior produtor de feijão do mundo em 2013, segundo dados da FAO (2014), com produção de 2.936 .444

Cultura Agronômica, Ilha Solteira, v.24, n.3, p.309-318, 2015 
toneladas, ficando atrás de Mianmar e da Índia. Os diferentes níveis de tecnologia usados e a instabilidade da produção contribuem para a baixa produtividade média, estimada em $1.033 \mathrm{~kg} \mathrm{ha}^{-1}$ (CONAB, 2014). Sendo assim, o uso da irrigação pode permitir a cultura expressar todo o seu potencial produtivo, reduzindo o efeito da má distribuição de chuvas, e possibilitando maiores rendimentos e estabilidade da produção.

Dentre os diversos fatores que afetam a produção da cultura, a água disponível no solo para a planta é um dos mais importantes. A FAO (2012) relacionou a produtividade das culturas com o uso da água propondo, uma equação simples em que a relaciona o rendimento real da produtividade de grãos submetidos ao estresse hídrico e o rendimento máximo da cultura sem estresse hídrico, em função da relação entre a evapotranspiração real da cultura submetida a estresse hídrico e a evapotranspiração máxima da cultura sem estresse hídrico, caracterizando um fator de resposta da cultura ao déficit hídrico (Ky). Ou seja, a queda de rendimento da produtividade esta ligada a queda da evapotranspiração potencial em relação a real.

O valor de Ky pode ser calculado para cada fase da cultura, ou pode ser calculado um valor único se o estresse ocorrer durante todo ciclo da cultura. No caso do ciclo do feijoeiro, o valor referência da FAO é 1,15, porém diferentes valores são relatados pela International Atomic Energy Agency (FAO, 2012) em experimentos em diferentes países ou diferentes regiões de um mesmo país, cujos valores variaram de 0,59 a 1,43.

Objetivou medir a evapotranspiração (ETr) e a água total disponível (AD) do feijoeiro sob seis níveis de estresse hídrico durante o ciclo da cultura, avaliando, também, a produtividade de grãos e de matéria seca da parte aérea, sob os mesmos níveis de estresse hídrico, e obtenção do fator de resposta (Ky) do feijoeiro.

\section{MATERIAL E MÉTODOS}

\section{Local e cultura}

O trabalho foi realizado em casa de vegetação no Câmpus II da Faculdade de Engenharia de Ilha Solteira, da Universidade Estadual Paulista "Júlio de Mesquita Filho" (UNESP). Utilizou-se no trabalho o feijão carioca, cultivar BRSMG Majestoso.

\section{Delineamento estatístico}

O delineamento estatístico utilizado foi inteiramente casualizado, constituído por seis tratamentos e quatro repetições, descritos a seguir:

T0 - reposição de $100 \%$ da transpiração, medida num período cuja depleção da água no solo foi entre 50 e $60 \%$ da Água Total Disponível (AD), tratamento com a superfície superior do vaso vedada, com polietileno expandido, para evitar a evaporação da água do solo;

T1 - rega diária de $100 \%$ da evapotranspiração;

T2 - rega de $100 \%$ da evapotranspiração, medida num período cuja depleção da água no solo foi entre 50 e $60 \%$ da $\mathrm{AD}$; 
T3 - rega com reposição de $75 \%$ em relação à T2;

$\mathrm{T} 4$ - rega com reposição de $50 \%$ em relação à $\mathrm{T} 2$;

T5 - rega com reposição de $30 \%$ em relação à T2.

\section{Desenvolvimento}

Foram utilizados vasos de 10 litros com Latossolo Vermelho distrófico (LVd), sendo conduzida uma planta por vaso com semeadura realizada em junho de 2012.

O solo, antes de ser colocado nos vasos, foi passado em peneira de $4 \mathrm{~mm}$ de malha, homogeneizado e secado em terreiro até atingir a umidade residual. Foi adicionado aos vasos $10 \mathrm{~kg}$ de solo seco, aproximadamente $7 \mathrm{~L}$ de solo por vaso. Depois, o solo nos vasos foi saturado (umidade de saturação) e deixado drenar até a umidade da capacidade de campo, sendo coberta, com polietileno expandido, a parte superior dos mesmos para evitar a perda por evaporação. Ao se obter pesagens sucessivas constantes, calculou-se a umidade à capacidade de campo.

Amostras do solo foram enviadas ao laboratório para análise de fertilidade, análise granulométrica e para obtenção da umidade do solo no ponto de murcha permanente. As adubações foram realizadas na semeadura e no início do estado fenológico V4 (terceira folha trifoliolada) e R8 (enchimento de grãos), seguindo as recomendações de Raij et al. (1997), não sendo a adubação limitante para o desenvolvimento da cultura.

Após a semeadura, os vasos foram mantidos em condições adequadas de umidade para o desenvolvimento das plantas até a fase fenológica V3 (emissão da primeira folha trifoliada). Dessa fase em diante os tratamentos foram diferenciados.

As pesagens foram feitas diariamente, entre 17 e 18 horas, desde a semeadura até o fim do ciclo, sendo a diferença correspondente à evapotranspiração diária em kg por planta, haja vista que não era adicionada água além da capacidade de campo em nenhum tratamento. Sempre que se fez necessária a reposição de água às plantas de cada tratamento, o volume foi aplicado com referência à diferença de pesagens obedecendo os percentuais da $\mathrm{AD}$ de cada tratamento. Assim, o cálculo para conversão de $\mathrm{kg}$ por planta para lâmina, em mm, da evapotranspiração total da cultura no ciclo foi conforme a Equação 1:

ETr total $(\mathrm{mm})=\frac{\text { Pt } \times 10^{-\mathrm{s}} \times 200000}{10000 \times 10^{-\mathrm{s}}}$

Em que: Pt - peso total das ETr diárias $\left(\mathrm{kg}_{\mathrm{k}} \mathrm{planta}^{-1}\right) ; 10^{-3}$ - volume de água por unidade de massa $\left(\mathrm{m}^{3} \mathrm{~kg}^{-1}\right) ; 200.000$ - população de plantas considerada (plantas ha ${ }^{-1}$ ); 10.000 - conversão de área $\left(\mathrm{m}^{2} \mathrm{ha}^{-1}\right) ; 10^{-3}$ - conversão $\left(\mathrm{m} \mathrm{mm}^{-1}\right)$.

No final do ciclo da cultura, as vagens de cada parcela foram extraídas e pesadas considerando a umidade de $13 \%$ à base úmida. Conforme pode ser vista na Eq. (2), considerou-se uma população de 200.000 plantas por hectare, que foi utilizada para extrapolar a produtividade de grãos e matéria seca da parte aérea de quilogramas por planta para quilogramas por hectare. Para cálculo da produtividade de matéria seca foi retirada a parte área das plantas, secada em estufa a $60{ }^{\circ} \mathrm{C}$ por 48 horas e, posteriormente, pesadas.

Cultura Agronômica, Ilha Solteira, v.24, n.3, p.309-318, 2015 
A sensibilidade da cultura ao déficit hídrico é estimada utilizando-se a Equação 2, descrita por Doorenbos e Kassam (1994), que quantifica a relação entre a redução do rendimento relativo e o déficit de evapotranspiração:

$\mathrm{Ky}=\frac{\left(1-\frac{Y_{Y}}{Y_{p}}\right)}{\left(1-\frac{B T r}{B T_{p}}\right)}$

Em que: Ky - fator de resposta da cultura ao déficit hídrico; $\mathrm{Yr}$ - rendimento real da cultura nos tratamentos submetidos ao estresse hídrico, em $\mathrm{kg} \mathrm{ha}^{-1} ; \mathrm{Yp}$ - rendimento máximo da cultura sem estresse hídrico, em $\mathrm{kg} \mathrm{ha}^{-1}$; ETr - evapotranspiração real (total) da cultura nos tratamentos submetidos ao estresse hídrico, em mm; ETp - evapotranspiração máxima da cultura sem estresse hídrico, em mm.

\section{Análise estatística}

O estudo estatístico envolveu análises de variâncias, teste de comparação de médias (Tukey) e de regressões, com ajuste de equações lineares e quadráticas que apresentaram níveis de significância de no mínimo $5 \%$ de probabilidade pelo teste $\mathrm{F}$, sendo escolhidas as de maior coeficiente de determinação (R2) com significado biológico.

\section{RESULTADOS E DISCUSSÃO}

Lâmina de irrigação, evapotranspiração e água total disponível versus produtividade de grãos e matéria seca da parte aérea

É demonstrado que a evapotranspiração (Equação 1) da cultura decresceu linearmente em relação a água disponível do solo (AD), consequentemente, as produtividades de grãos e de matéria seca aumentaram significamente com a elevação da evapotranspiração no ciclo, lâmina de irrigação e água total disponível (Tabela 1).

Tabela 1. Produtividade de grãos e matéria seca da parte aérea em função da lâmina de irrigação, evapotranspiração (ETr) no ciclo e água total disponível (AD).

\begin{tabular}{|c|c|c|c|c|c|c|c|}
\hline \multirow{2}{*}{ Tratamento } & \multirow{2}{*}{$\begin{array}{c}\text { Lâmina de } \\
\text { Irrigação } \\
(\mathrm{mm})\end{array}$} & \multirow{2}{*}{$\begin{array}{c}\text { ETr } \\
(\mathrm{mm})\end{array}$} & \multirow{2}{*}{$\begin{array}{l}\mathrm{AD} \\
(\%)\end{array}$} & \multicolumn{2}{|c|}{ Produtividade } & \multicolumn{2}{|c|}{ Matéria Seca } \\
\hline & & & & $\left(\right.$ g planta $\left.^{-1}\right)$ & $\left(\mathrm{kg} \mathrm{ha}^{-1}\right)$ & $\left(\right.$ g planta $\left.^{-1}\right)$ & $\left(\mathrm{kg} \mathrm{ha}^{-1}\right)$ \\
\hline 0 & 240 & 248 & 68,3 & 15,134 & $3.027 \mathrm{a}$ & 42,528 & $8.506 \mathrm{a}$ \\
\hline 1 & 393 & 400 & 70,4 & 13,581 & $2.716 \mathrm{~b}$ & 42,650 & $8.530 \mathrm{a}$ \\
\hline 2 & 367 & 378 & 65,3 & 13,252 & $2.650 \mathrm{~b}$ & 38,753 & $7.751 \mathrm{~b}$ \\
\hline 3 & 289 & 306 & 57,7 & 10,928 & $2.186 \mathrm{c}$ & 37,073 & $7.415 \mathrm{bc}$ \\
\hline 4 & 228 & 251 & 43,5 & 10,214 & $2.043 \mathrm{~d}$ & 35,888 & $7.178 \mathrm{c}$ \\
\hline 5 & 171 & 198 & 33,5 & 8,791 & $1.758 \mathrm{e}$ & 30,365 & $6.073 \mathrm{~d}$ \\
\hline CV\% & & & & & 1,62 & & 2,19 \\
\hline
\end{tabular}

Médias seguidas de mesma letra na coluna, não diferem entre si, ao nível de 5\%, pelo teste de Tukey.

Com o aumento da água disponível do solo ocorreu aumento da evapotranspiração, o que concomitantemente influenciou na produção da cultura. A relação da evapotranspiração 
e a água disponível (AD) do solo se deve ao aumento do módulo do potencial mátrico do solo, tornando o fluxo da água no sistema solo-planta-atmosfera menor, o que proporciona menor concentração de vapor d'água no mesófilo da folha menor que a saturação, e consequentemente, redução na taxa de transpiração, além das maiores perdas por evaporação devido à concentração de umidade nas proximidades da superfície do solo (FISCHER FILHO et al., 2014).

Cabe observar que as pequenas diferenças entre os valores da lâmina de irrigação total e da evapotranspiração são explicadas pela diferença de umidade do solo entre a semeadura e a colheita, uma vez que no final do ciclo a irrigação cessou, porém a evaporação permaneceu, ainda que pequena. Em tese, o tratamento 1 tinha o propósito de medir a evapotranspiração potencial da cultura, estimar a reposição de $100 \%$ da evapotranspiração a cada 24 horas, fato que permitiria manter a umidade do solo próxima à capacidade de campo, ou seja, $\mathrm{AD} \cong 100 \%$. Todavia, na prática, a reposição diária de água não foi suficiente para tal, devido a alta evapotranspiração da cultura que chegou a 6,6 e 5,7 mm $\mathrm{dia}^{-1}$ nos tratamentos 1 e 2 , respectivamente, valor relativamente alto para a cultura de inverno, e, também, a um problema na refrigeração da casa de vegetação, em que elevou-se a temperatura dentro da mesma.

Em relação à produtividade de grãos, verificou-se que os tratamentos 1 e 2 não diferiram estatisticamente, isso pode ser explicado pelo exposto no parágrafo anterior. Como a $\mathrm{AD}$ no tratamento $1(70,4 \%)$ ficou aquém dos $100 \%$ e mais próxima a do tratamento $2(65,3 \%)$, as produtividades se equivaleram. Todavia, os tratamentos 1 e 2 superaram a produtividade do tratamento 3, que superou a do tratamento 4 e este, por fim, superou a do tratamento 5 , mostrando que o estresse hídrico foi o fator determinante para a queda na produtividade.

Calvache et al. (1997) citam que o estresse hídrico na etapa de enchimento de vagens produz abortamento de vagens jovens e produção de vagens chochas nas pontas, além disso, a deficiência de água durante a etapa final de enchimento de grão (R8) e maturidade (R9) provoca menor número de grãos devido ao aborto destes na ponta. Corroborando com os resultados deste trabalho, Santana et al. (2009) constataram o efeito significativo na produtividade de feijoeiro comum em relação às lâminas de reposição de água no estádio vegetativo R9 (maturação), concluindo que o aumento da produção é em função do nível de reposição de água, atingindo o máximo com reposição de $100 \%$ da água consumida.

Ainda em relação à produtividade, verificou-se que o tratamento 0 (apenas transpiração) apresentou a maior produtividade. Isso pode ter ocorrido devido a menor oscilação diária da disponibilidade de água no solo durante o ciclo da cultura. Possivelmente, o fato de a superfície do solo ficar vedada a partir da fase V4 impede a formação de uma camada superficial ressecada pela evaporação, possibilitando o sistema radicular explorar melhor o volume de solo no vaso. Andrade (2002), ao estudar o consumo relativo de água do feijoeiro no plantio direto em função da porcentagem de cobertura morta do solo, verificou que a evapotranspiração apresentou valor menor à medida que se aumentou a porcentagem de cobertura do solo pela palhada, portanto, ocorre um aumento da 
eficiência no uso da água com a redução do consumo.

Devido ao fato de as lâminas de irrigação aplicadas apresentarem caráter quantitativo e, ainda, considerando que a evapotranspiração ocorrida no ciclo estava estreitamente relacionada à lâmina aplicada, efetuou-se a análise de variância seguida de regressão relacionando a lâmina de irrigação no ciclo da cultura versus a produtividade, cuja síntese é mostrada na Tabela 2, a seguir.

Tabela 2. Síntese da análise de variância e regressão da produtividade do feijoeiro (Yr, em $\mathrm{kg} \mathrm{ha}^{-1}$ ) em função da lâmina de irrigação ( $\mathrm{I}$, em mm).

\begin{tabular}{ccccc}
\hline Modelo & Equação & NMS & $\mathrm{R}^{2}(\%)$ & $\mathrm{CV}(\%)$ \\
\hline Linear & $\mathrm{Yr}=4,352 \mathrm{I}+1010$ & 0,000 & 89,52 & 1,62 \\
Quadrático & $\mathrm{Yr}=0,003434 \mathrm{I}^{2}+2,395 \mathrm{I}+1265$ & 0,058 & 98,67 & 1,62 \\
\hline
\end{tabular}

Embora a função quadrática ajustada explique $98,67 \%$ dos resultados, ela não foi significativa, enquanto a linear foi significativa e apresentou $\mathrm{R}^{2}=89,52 \%$. Na realidade, era esperada significância do modelo quadrático, que representaria adequadamente a produtividade do feijoeiro em resposta ao acréscimo da lâmina de irrigação durante o ciclo, ou seja, com o aumento da irrigação (e, consequentemente da evapotranspiração) aumentase a produtividade até um nível máximo seguida de queda, em que haveria excesso de irrigação prejudicando a cultura. Contudo, o modelo linear, que não expressa adequadamente o processo, mas foi significativo permitiu, dentro dos limites inferior e superior das lâminas de irrigação aplicadas no experimento, a estimativa da produtividade.

De maneira similar à produtividade de grãos, e com base na Tabela 1, a quantidade de matéria seca da parte aérea, excluindo vagens e grãos, apresentou diferenças significativas entre os tratamentos, verificando-se que os tratamentos submetidos às maiores disponibilidades hídricas obtiveram maior acúmulo de biomassa. Observou-se no tratamento 5 (33,5\% de $\mathrm{AD})$ uma redução mais acentuada da biomassa da parte aérea do que nos demais, indicando a sensibilidade ao estresse hídrico. Os tratamentos 0 e 1 foram os que tiveram as maiores produções de matéria seca da parte aérea. Diferentemente da produtividade de grãos, o tratamento 1 foi superior ao 2 na biomassa acumulada. Por sua vez, o tratamento 2 foi superior ao 4 e este ao 5, contudo foi igual estatisticamente ao 3 .

Considerando o caráter quantitativo das lâminas de irrigação aplicadas, como o foi para a produtividade, efetuou-se a análise de variância seguida de regressão relacionando a produção de matéria seca da parte aérea da cultura versus a lâmina de irrigação no ciclo, cuja síntese é mostrada na Tabela 3, a seguir.

Tabela 3. Síntese da análise de variância e regressão da produção de matéria seca da parte aérea do feijoeiro (Ms, em $\mathrm{kg} \mathrm{ha}^{-1}$ ) em função da lâmina de irrigação (I, em mm)

\begin{tabular}{ccccc}
\hline Modelo & Equação & NMS & $\mathrm{R}^{2}(\%)$ & $\mathrm{CV}(\%)$ \\
\hline Linear & $\mathrm{Ms}=9,12 \mathrm{I}+4748$ & 0,000 & 89,52 & 2,39 \\
Quadrático & $\mathrm{Ms}=-0,0159 \mathrm{I}^{2}+18,17 \mathrm{I}+3569$ & 0,067 & 90,47 & 2,39 \\
\hline
\end{tabular}

À semelhança do que ocorreu em relação à produtividade de grãos, a função quadrática não foi significativa. Contudo, o modelo linear, que não expressa adequadamente Cultura Agronômica, Ilha Solteira, v.24, n.3, p.309-318, 2015 
o fenômeno, foi significativo e permite estimar com boa precisão a produção de biomassa em relação às lâminas de irrigação dentro do intervalo de lâminas de irrigação ensaiadas.

Sediyama et al. (1998), citam que as plantas reduzem a evapotranspiração automaticamente quando a taxa de absorção de água do solo pelo sistema radicular torna-se menor que a transpiração. Elas fecham seus estômatos à medida que o teor de água no tecido da folha diminui. Esse fechamento dos estômatos inibe a penetração de $\mathrm{CO}_{2}$ no interior das folhas restringindo o processo de fotossíntese e, consequentemente, o crescimento celular. Portanto, redução na transpiração pode significar, também, redução na produção. A senescência foliar no período de enchimento das vagens é uma das principais causas de aborto dessas e, consequente, de baixa produtividade do feijoeiro sob estresse, conforme Guimarães (1996).

\section{Fator de resposta da cultura ao déficit hídrico $(\mathrm{Ky})$}

Para se calcular o fator de resposta de uma cultura ao déficit hídrico (Ky), além da necessidade de se conhecer o valor da evapotranspiração potencial do feijoeiro no ciclo (ETp) que foi estimada em $557 \mathrm{~mm}$, por meio de regressão dos valores da evapotranspiração versus água disponível (AD), também foi necessário o conhecimento da produtividade potencial do feijoeiro nas condições do experimento. $O$ tratamento 1 tinha o propósito de medir a evapotranspiração potencial do feijoeiro, todavia, pelas razões já expostas, a evapotranspiração potencial teve que ser estimada, fato que ocorreu também com a produtividade potencial, cuja estimativa foi com base na regressão dos valores da produtividade real versus a água disponível (AD), cuja síntese da análise de variância e regressão é mostrada na Tabela 4. Mesmo que a regressão quadrática tenha apresentado significância, por não estar em conformidade com o esperado na prática, optou-se pela regressão linear, também significativa no limite de 5\%. Substituindo-se o valor de $100 \%$ da $\mathrm{AD}$ na equação, a produtividade potencial estimada foi de $3.451 \mathrm{~kg} \mathrm{ha}^{-1}$, valor este que foi utilizado nos cálculos da redução relativa de produtividade do feijoeiro.

Tabela 4. Síntese da análise de variância e regressão da produtividade do feijoeiro (Yr, em $\mathrm{kg} \mathrm{ha}^{-1}$ ) em função da água total disponível no solo (AD, em \%).

\begin{tabular}{ccccc}
\hline Modelo & Equação & NMS & $\mathrm{R}^{2}(\%)$ & $\mathrm{CV}(\%)$ \\
\hline Linear & $\mathrm{Yr}=25,7 \mathrm{AD}+881$ & 0,000 & 93,54 & 1,62 \\
Quadrático & $\mathrm{Yr}=0,3338 \mathrm{AD}^{2}-8,944 \mathrm{AD}+1715$ & 0,000 & 94,95 & 1,62 \\
\hline
\end{tabular}

Com isso, o Ky foi calculado em cada tratamento e cada repetição, possibilitando efetuar a análise de variância seguida de regressão linear, mostrada na Tabela 5, na qual foi possível a obtenção do Ky geral $(\mathrm{Ky}=0,7635)$, que correspondeu à derivada da função.

Tabela 5. Síntese da análise de variância e regressão do déficit de produtividade do feijoeiro $(1-\mathrm{Yr} / Y \mathrm{p})$ em função do déficit de evapotranspiração $(1-\mathrm{ETr} / \mathrm{ETp})$.

\begin{tabular}{ccccc}
\hline Modelo & Equação & NMS & $\mathrm{R}^{2}(\%)$ & $\mathrm{CV}(\%)$ \\
\hline Linear & $(1-\mathrm{Yr} / \mathrm{Yp})=0,7635(1-\mathrm{ETr} / \mathrm{ETp})$ & $1,2 \mathrm{E}-15$ & 97,35 & 2,39 \\
\hline
\end{tabular}

Cultura Agronômica, Ilha Solteira, v.24, n.3, p.309-318, 2015 
Na Tabela 6 são mostrados os valores de Ky (Equação 2) de cada tratamento (Ky médio) e dos déficits de evapotranspiração e produtividade, o que possibilitou a confecção da Figura 1, apresentada a seguir.

Tabela 6. Fator de resposta da cultura $(\mathrm{Ky})$ em função da relação entre a redução relativa da produtividade [1- (Yr/Yp)] com o déficit relativo de evapotranspiração [1-(ETr/ETp)].

\begin{tabular}{cccccccc}
\hline Tratamentos & $\begin{array}{c}\mathrm{ETr} \\
\left(\mathrm{mm} \mathrm{dia}^{-1}\right)\end{array}$ & $\frac{\mathrm{ETr}}{\mathrm{ETp}}$ & $1-\left(\frac{\mathrm{ETr}}{\mathrm{ETp}}\right)$ & $\begin{array}{c}\mathrm{Yr} \\
\left(\mathrm{kg} \mathrm{ha}^{-1}\right)\end{array}$ & $\frac{\mathrm{Yr}}{\mathrm{Yp}}$ & $1-\left(\frac{\mathrm{Yr}}{\mathrm{Yp}}\right)$ & $\mathrm{Ky}$ \\
\hline Máx. estim. & 557 & 1 & 0 & 3.451 & 1 & 0 & - \\
1 & 400 & 0,718 & 0,282 & 2.716 & 0,787 & 0,213 & 0,76 \\
2 & 378 & 0,679 & 0,321 & 2.650 & 0,768 & 0,232 & 0,72 \\
3 & 306 & 0,550 & 0,450 & 2.186 & 0,633 & 0,367 & 0,81 \\
4 & 251 & 0,451 & 0,549 & 2.043 & 0,592 & 0,408 & 0,74 \\
\hline
\end{tabular}

Analisando a Tabela 6, verifica-se que o déficit relativo de produtividade cresceu com o déficit relativo de evapotranspiração, como era esperado do tratamento 1 ao 5. Porém, a divisão de um pelo outro, correspondente ao Ky, permite observar que o maior Ky foi o do tratamento 3, ou seja, o déficit relativo de produtividade foi o mais acentuado em relação ao déficit relativo de evapotranspiração, em outras palavras, foi o tratamento em que o déficit de evapotranspiração causou mais déficit de produtividade marginal.

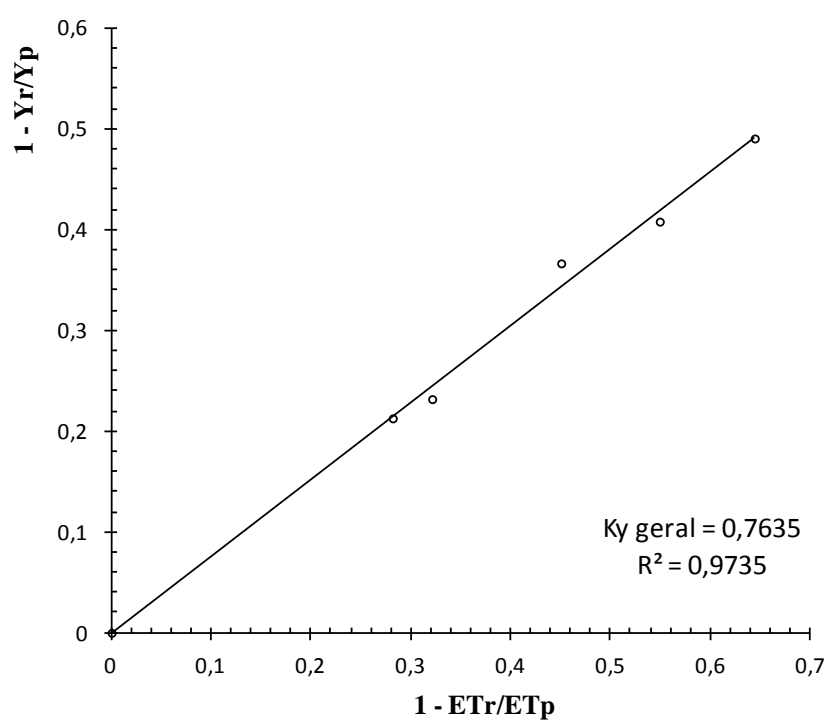

Figura 1. Redução relativa da produtividade [1- (Yr/Yp)] em função do déficit relativo de evapotranspiração [1-(ETr/ETp)]. A tangente da reta corresponde ao Ky geral (todos os tratamentos) e os marcadores (pontos sem preenchimento) os pares $\{[1-(\mathrm{Yr} / \mathrm{Yp})]$; $[1-$ $(\mathrm{ETr} / \mathrm{ETp})]\}$.

Em relação à Figura 1, o valor do Ky geral do feijoeiro inferior à unidade significa que a cultura é relativamente tolerante ao déficit hídrico, que correspondem às culturas em que uma unidade de déficit hídrico causa menos que uma unidade de déficit de produtividade, fazendo-as menos sensíveis à disponibilidade hídrica do ciclo como um todo. 
Resultados semelhantes foram obtidos por Cordeiro et al. (1998) que, ao analisarem o fator de sensibilidade ao déficit hídrico do feijão caupi, verificaram que todos os valores de coeficientes de sensibilidade de Ky encontrados para os tratamentos aplicados foram inferiores a 1, mostrando baixa sensibilidade da cultura ao estresse hídrico. Já Calvache et al. (1997), ao avaliarem o efeito da deficiência hídrica e da adubação nitrogenada na produtividade e eficiência do uso da água em feijão, observaram que grande parte dos tratamentos apresentaram certa resistência ao estresse hídrico, haja vista que obtiveram Ky inferiores a 1. Sendo que o tratamento que apresentou queda relativa de evapotranspiração em $21 \%$, apresentou um decréscimo relativo de rendimento de $1 \%$, originando um fator de resposta de 0,06 , colocando-o como o melhor tratamento em termos de produtividade. Ou seja, podem-se obter produtividades muito próximas às máximas, com estresse moderado de água no solo na etapa vegetativa, permitindo economia de água na irrigação.

\section{CONCLUSÃO}

A evapotranspiração no ciclo da cultura decresceu com a redução da água total disponível (AD). E o aumento da AD proporciona um incremento da produtividade de grãos e da matéria seca da parte área da cultura.

O tratamento com a superfície do solo vedada apresentou melhor eficiência no uso da água, portanto, ressalta-se a importância da cobertura do solo em sistema de cultivo como o plantio direto, minimizando a perda de água do solo por evaporação.

$\mathrm{O}$ fator de resposta da cultura ao déficit hídrico $(\mathrm{Ky})$ foi 0,7635 , o que qualifica o feijoeiro como planta relativamente resistente ao estresse hídrico, considerando o ciclo completo da cultura.

\section{REFERÊNCIAS BIBLIOGRÁFICAS}

ANDRADE, R. S.; MOREIRA, J. A. A.; STONE, L. F.; CARVAlHO, J. A. Consumo relativo de água do feijoeiro no plantio direto em função da porcentagem de cobertura morta do solo. Revista Brasileira de Engenharia Agrícola e Ambiental, Campina Grande, v. 6, n. 1, p.35-38, 2002.

CALVACHE, A. M.; REICHARDT, K.; MALAVOLTA, E.; BACCHI, O. O. S. Efeito da deficiência hídrica e da adubação nitrogenada na produtividade e na eficiência do uso de água em uma cultura do feijão. Ciência Agrícola, Piracicaba, v. 54, n. 3, p.232-240, 1997.

COMPANHIA NACIONAL DE ABASTECIMENTO - CONAB. Acompanhamento da Safra Brasileira de Grãos 2013/2014 - Décimo segundo Levantamento. Brasília: CONAB, 2014. $131 \mathrm{p}$.

CORDEIRO, L. G.; BEZERRA, F. M. L.; SANTOS, J. J. A.; MIRANDA, E. P. Fator de sensibilidade ao déficit hídrico da cultura do feijão caupi (Vigna unguiculata (L) Walp).

Cultura Agronômica, Ilha Solteira, v.24, n.3, p.309-318, 2015 
Revista Brasileira de Engenharia Agrícola e Ambiental. Campina Grande, v. 2, n. 2, p. 153-157, 1998.

DOORENBOS, J.; KASSAN, A. H. Efeito da Água no rendimento das culturas. Tradução: GHEYI, H. R.; SOUSA, A. A.; DAMASCENO, F. A. V.; MEDEIROS, J. F. Campina Grande: UFPB, 1994. 306 p.

FISCHER FILHO, J. A.; ZOCOLER, J. L.; POLONI, N. M.; FURLANI JÚNIOR, E. Evapotranspiração e disponibilidade hídrica em feijoeiro (Phaseolus vulgaris) sob estresse hídrico. Revista Brasileira de Agricultura Irrigada, Fortaleza, v. 8, n. 5, p.366-376, 2014.

FREITAS, F. O. Evidências genético-arqueológicas sobre a origem do feijão comum no Brasil. Pesquisa Agropecuária Brasileira, Brasília, v. 41, n. 7, p.1199-1203, 2006.

FOOD AND AGRICULTURE ORGANIZATION - FAO. Crop yield response to water. Rome: FAO, 2012. 500 p. (Irrigation and drainage paper, 66)

FOOD AND AGRICULTURE ORGANIZATION - FAO. Produção de produtos alimentares e agrícolas. 2014. Disponível em: <http://faostat3.fao.org/faostatgateway/go/to/browse/Q/QC/E>. Acesso em: 03 jun. 2014.

GUIMARÃES, C. M. Relações hídricas. In: ARAUJO, R. S.; RAVA, C. A.; STONE, L. F.; ZIMMERMANN, M. J. O. (Org.). Cultura do feijoeiro comum no Brasil. Piracicaba: Potafos, 1996. p. 139-168.

RAIJ, B. VAN; CANTARElla, H.; QUAGGIO, J. A.; FURLANI, A. M. C. Recomendações de adubação e calagem para o estado de São Paulo. Campinas: Instituto Agronômico/Fundação IAC, 1997. 285 p.

SANTANA, M. J; CARVAlHO, J. A.; ANDRADE, M. J. B.; GERVÁSiO, G. G.; BRAGA, J. C.; LEPRI, E. B. Viabilidade técnica e econômica da aplicação de água na cultura do feijoeiro comum (Phaseolus vulgaris L.). Ciência e Agrotecnologia, Lavras, v. 33 , n. 2, p.532-538, 2009.

SEDIYAMA, G. C.; RIBEIRO, A.; LEAL, B. G. Relações clima-água-planta. In: FARIA, M. A.; SIlVA, E. L.; VILELA, L. A. A.; SIlVA, A. M. (Org.). Manejo de irrigação. Poços de Caldas: UFLA/SBEA, 1998. cap. 2, p. 46-85. 